\title{
Effect of ileal infusion of glycochenodeoxycholic acid on segmental transit, motility, and flow in the human jejunum and ileum
}

\author{
R PENAGini, R C SPILler, J J MISIEWICZ, AND P G FROST \\ From the Departments of Gastroenterology and Nutrition, and of Chemical Pathology, Central Middlesex \\ Hospital, London
}

SUMmary The hypothesis that the presence of glycochenodeoxycholic acid (GCDC) in the human Ileal bile acid concentrations showed a 54.0 (9-3)\% absorption of glycochenodeoxycholic acid by the been tested in healthy volunteers. Mean transit times, flow rates and intraluminal pressures in a 40 $\mathrm{cm}$ jejunal segment proximal $(n=6)$ and a $40 \mathrm{~cm}$ ileal segment distal $(n=6)$ to a GCDC infusion port were measured. During GCDC infusion $(60 \mu \mathrm{mol} / \mathrm{min})$ jejunal and ileal transit were markedly $(\mathrm{p}<0.05)$ delayed (31.6 (7.7), mean (SEM) v 14.5 (3.8) $\mathrm{min}$ and $37.0(5.7) v 21.0(3.5) \mathrm{min}$, respectively), segment volumes increased $(141.1(30 \cdot 2) v 59.2(9.9) \mathrm{ml}$ and $173.2(26.3) v 83.9(9.5)$ $\mathrm{ml} ; \mathrm{p}<0.05)$, while flow rates did not change significantly $(4.6(0.6) v 4.5(0.6) \mathrm{ml} / \mathrm{min}$ and $4.8(0.5) v$ $4 \cdot 2(0 \cdot 3) \mathrm{ml} / \mathrm{min}$, respectively). Ileal pressures (distal to the GCDC infusion port) decreased $(p<0.05)$ promptly $(1 \cdot 0(0 \cdot 1) \mathrm{min})$ after the start of GCDC infusion. Inhibition of jejunal motility was more gradual and reached significance $(p<0.05)$ only $30 \mathrm{~min}$ after beginning of the infusion. Ileal bile acid concentrations showed a $54 \cdot 0(9 \cdot 3) \%$ absorption of glycochenodeoxycholic acid by the $40 \mathrm{~cm}$ ileal segment. These observations suggest the existence of an intestinal control mechanism in healthy man, whereby presence of glycochenodeoxycholic acid in the ileum inhibits motility and delays transit in the jejunum and ileum.

We have previously shown ${ }^{1}$ that jejunal infusion of glycochenodeoxycholic acid prolonged jejunocaecal transit time and decreased jejunal motility. The inhibition of motility was delayed with respect to the start of the infusion, suggesting the posibility that the inhibitory effect could originate in the distal instestine. The ileum is known to be the site of a regulatory mechanism involving fat, ${ }^{23}$ likely to maximise absorption and prevent escape into the caecum of diarrhoeogenic compounds. ${ }^{4}$ In previous perfusion studies, chenodeoxycholic acid was found to inhibit water and electrolyte absorption from the human ileum. ${ }^{5}$ A short segment, however, was studied at

Address for correspondence: Dr R Penagini, Cattedra di Patologia Medica III, Istituto di Scienze Mediche, Padiglione Granelli, Via F. Sforza, 35, 20122 Milano, Italy.

Accepted for publication 14 October 1988. high infusion rate and an occlusive balloon was used, which is known to inhibit motility distal to it. ${ }^{6}$

The present study was designed to investigate whether ileal infusion of glycochenodeoxycholic acid (GCDC) had an effect on fed motility, transit time, and flow rate in the human jejunum and ileum.

\section{Methods}

\section{SUBJECTS}

Two sets of experiments on healthy adult volunteers were carried out. The first set (numbered 1-6) investigated the effect of ileal infusion of GCDC on the jejunum and the second set (numbered 7-12) investigated the effect on the ileum.

Ten healthy subjects (aged 21-26 yr; nine men) with no symptoms or past history of gastrointestinal disease entered the study, which was approved by the Brent Health District Ethical Committee. Eight sub- 
jects took part in one experiment only and the two remaining subjects underwent two experiments, one in each set. The maximal intestinal radiation dose received by each subject was equivalent to $20 \mathrm{mrad}$.

\section{TUBE DESIGN}

In all experiments the 12 lumen assembly of polyvinyl tubes (external diameter $=6 \mathrm{~mm}$ ) was composed of three triple lumen tubes (external diameter $=2 \mathrm{~mm}$; Dural Plastics, Australia) for recording of intraluminal pressure and infusion of test solutions, one $3 \mathrm{~mm}$ external diameter tube for aspiration, one $1 \mathrm{~mm}$ external diameter tube as an air bleed and one $2 \mathrm{~mm}$ external diameter tube for balloon inflation. The assembly included one radio-opaque tube to facilitate fluoroscopic localisation and was weighted at the end with a double balloon containing $1 \mathrm{ml}$ of mercury. Location of ports is expressed in centimetres from the orad end of the assembly.

Experiments 1-6 (Fig. 1a). The assembly featured: for the jejunum two infusion ports $(\mathrm{J}$ and $\mathrm{P})$ and one aspiration port (A) at 100,125 , and $140 \mathrm{~cm}$ respectively, and for the ileum one infusion port (I) at 170 $\mathrm{cm}$. Manometry ports were sited: for the jejunum (j1, $\mathrm{j} 2$, and j3) at $105,120,135 \mathrm{~cm}$; and for the ileum (i1, $\mathrm{i} 2$, and i3) at $167 \cdot 5,175,182 \cdot 5 \mathrm{~cm}$.

Experiments 7-12 (Fig. 2a). The assembly featured: for the jejunum one infusion port $(\mathrm{J})$ at 100 $\mathrm{cm}$; for the ileum two infusion ports ( $\mathrm{I}$ and $\mathrm{P})$ and one aspiration port (A) at 170,195 , and $210 \mathrm{~cm}$ respectively. Manometry ports for the ileum (i1-i5) were at $175,182 \cdot 5,190,197 \cdot 5$, and $205 \mathrm{~cm}$.

INTUBATION AND MANOMETRIC TECHNIQUE After an overnight fast all subjects swallowed the assembly of polyvinyl tubes. When the assembly entered the duodenum a small amount of air was injected into the balloon to accelerate progress of the tube, until the jejunal infusion port $(\mathrm{J})$ marked by a small radio-opaque plug advanced to about $10 \mathrm{~cm}$

\section{Experiments 1-6}

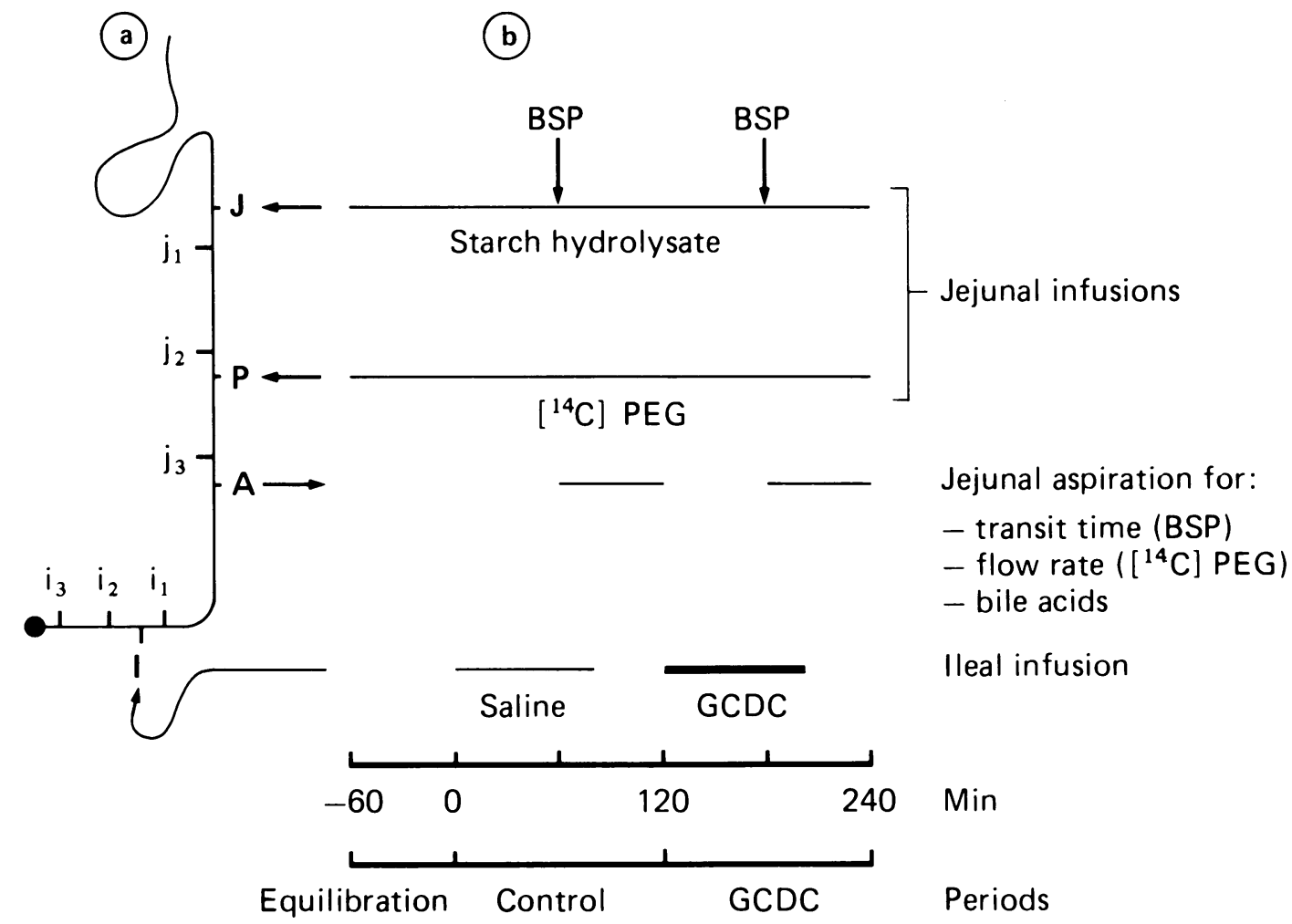

Fig. 1 Experiments $1-6$. (a) Tube design: $J=$ jejunal infusion port. $P=\left[{ }^{14} C\right] P E G$ infusion port. $A=$ aspiration port. $I=i l e a l$ infusion port. $j 1, j 2, j 3=$ jejunal manometry ports. $i 1, i 2, i 3=i l e a l$ manometry ports. (b) Design of the experiments: $G C D C=$ glycochenodeoxycholic acid. 
Experiments 7-12

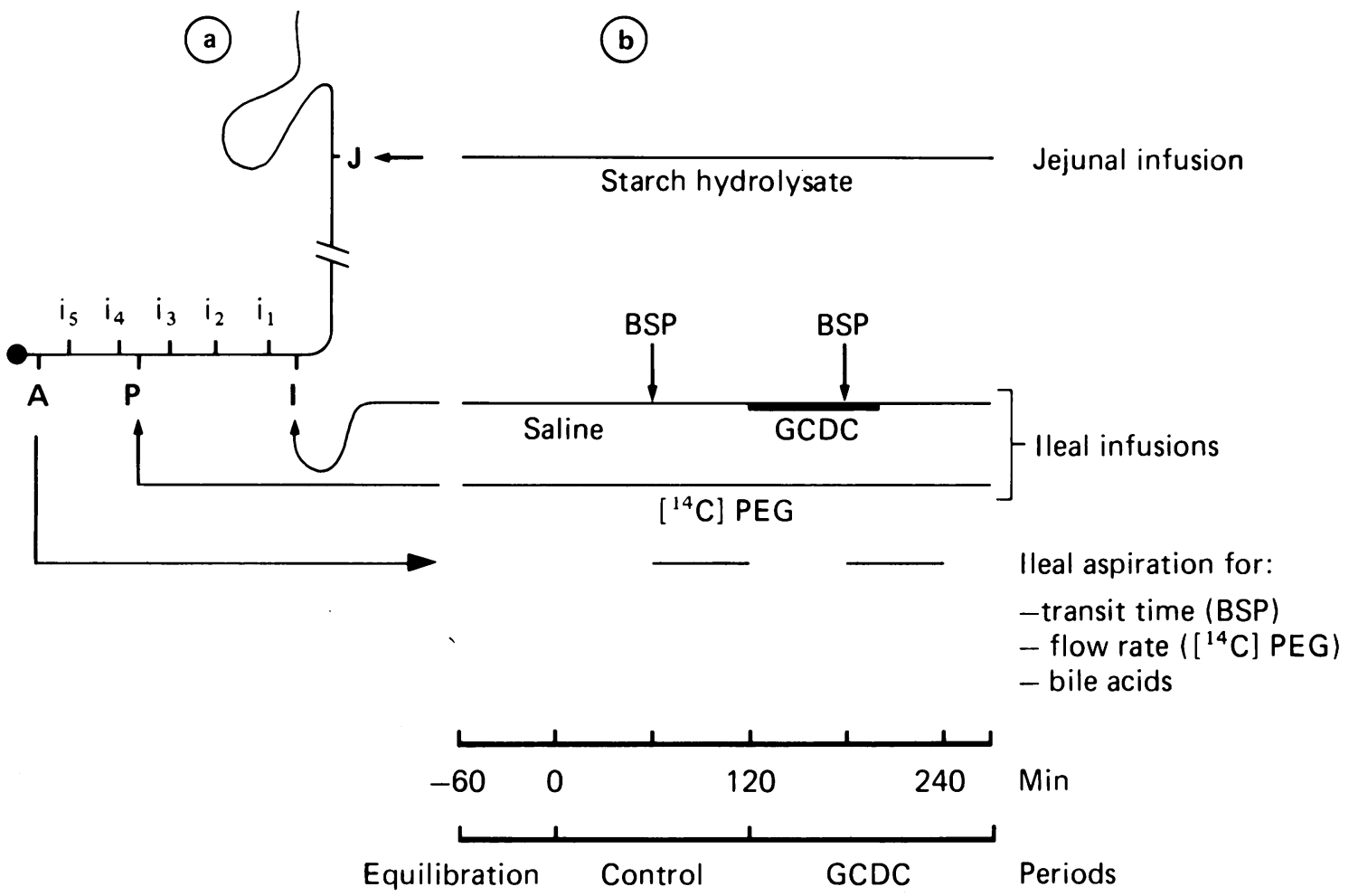

Fig. 2 Experiments 7-12. (a) Tube design: $J=$ jejunal infusion port. $I=$ ileal infusion port. $P=\left[{ }^{14} C\right] P E G$ infusion port. $A=$ aspiration port. i1 , i2, i3, i4, i5=ileal manometry ports. (b) Design of the experiments: $G C D C=$ glycochenodeoxycholic acid.

beyond the duodeno-jejunal flexure. The balloon was then deflated and the mercury aspirated completely. The manometry tubes were perfused with water at $0.15 \mathrm{ml} / \mathrm{min}$ by a low compliance pneumohydraulic capillary infusion system (Mui Scientific), permitting a response time of $35 \mathrm{mmHg} / \mathrm{sec}$. The tubes were connected to external pressure transducers (Statham P23ID) and signals recorded on a polygraph (Grass, model 7) throughout all experiments. A pneumatic belt tied around the chest of the subject monitored respiration.

\section{CONDUCT OF EXPERIMENTS}

\section{Experiments 1-6 (Fig. 1b)}

Each study comprised an equilibration period (one hour), a control period (two hours), and a GCDC period (two hours). After the tube had reached its position (median $4.5 \mathrm{~h}$, range $3.5-5.5 \mathrm{~h}$ ), jejunal perfusion was started through $J$ at $4 \mathrm{ml} / \mathrm{min}$ with a solution containing starch hydrolysate (Polycal,
Nutricia; $2 \mathrm{kcal} / \mathrm{min}$ ) and through $P$ at $1 \mathrm{ml} / \mathrm{min}$ with saline containing $\left[{ }^{14} \mathrm{C}\right] \mathrm{PEG}$ and was continued throughout the study. Starch hydrolysate was added to the jejunal infusate to induce and maintain a fed pattern of motility. One hour into the control and GCDC periods a bolus of bromosulphthalein (BSP, $50 \mathrm{mg}$ ) was injected rapidly through $\mathrm{J}$ for the measurement of jejunal transit.

During the first 80 minutes of control and GCDC periods the ileum was perfused through I at $2 \mathrm{ml} / \mathrm{min}$ with saline and a solution containing GCDC, total dose $5 \mathrm{mmol}$ (concentration $30 \mathrm{mmol} / \mathrm{l}$ ), respectively. The composition of all test solutions is shown in Table 1.

Aspiration of jejunal fluid was done throughout the study through port A with the help of an air bleed. The aspirate obtained during the first hour of control and GCDC periods was discarded, while in the second hour of both periods $2 \mathrm{ml}$ samples every two minutes were collected for analysis of BSP, $\left[{ }^{14} \mathrm{C}\right] \mathrm{PEG}$ and bile acids. 
Table 1 Composition of test solutions

\begin{tabular}{|c|c|c|}
\hline & Control & $G C D C$ \\
\hline \multicolumn{3}{|l|}{ Experiments $1-6$} \\
\hline \multicolumn{3}{|l|}{$\mathrm{J}$ port $(4 \mathrm{ml} / \mathrm{min})$} \\
\hline Polycal* $(\mathrm{g} / \mathrm{l})$ & 131 & 131 \\
\hline $\mathrm{NaCl}(\mathrm{mmol} / \mathrm{l})$ & 60 & 60 \\
\hline Lactulose $(\mathrm{g} / \mathrm{l})$ & 15 & 15 \\
\hline \multicolumn{3}{|l|}{ P port $(1 \mathrm{ml} / \mathrm{min})$} \\
\hline $\mathrm{NaCl}(\mathrm{mmol} / \mathrm{l})$ & 150 & 150 \\
\hline$\left[{ }^{1+} \mathrm{C}\right] \mathrm{PEG}(\mu \mathrm{Ci} / \mathrm{l})$ & 10 & 10 \\
\hline \multicolumn{3}{|l|}{ I port $(2 \mathrm{ml} / \mathrm{min})$} \\
\hline $\mathrm{NaCl}(\mathrm{mmol} / \mathrm{l})$ & 150 & 120 \\
\hline $\mathrm{GCDC}+(\mathrm{mmol} / \mathrm{l})$ & - & 30 \\
\hline \multicolumn{3}{|l|}{ Experiments $7-12$} \\
\hline \multicolumn{3}{|l|}{$\mathrm{J}$ port $(2 \mathrm{ml} / \mathrm{min})$} \\
\hline $\mathrm{NaCl}(\mathrm{mmol} / \mathrm{l})$ & $\begin{array}{r}202 \\
30\end{array}$ & $\begin{array}{r}202 \\
30\end{array}$ \\
\hline \multicolumn{3}{|l|}{ I port $(4 \mathrm{ml} / \mathrm{min})$} \\
\hline $\mathrm{NaCl}(\mathrm{mmol} / \mathrm{l})$ & 120 & $105 \ddagger$ \\
\hline Lactulose $(\mathrm{g} / \mathrm{l})$ & 15 & 15 \\
\hline $\mathrm{GCDC} \dagger(\mathrm{mmol} / \mathrm{l})$ & - & $15 \ddagger$ \\
\hline \multicolumn{3}{|l|}{ P port ( $1 \mathrm{ml} / \mathrm{min})$} \\
\hline $\mathrm{NaCl}(\mathrm{mmol} / \mathrm{l})$ & 150 & 150 \\
\hline$\left[{ }^{[+} \mathrm{C}\right]$ PEG $(\mu \mathrm{Ci} / \mathrm{l})$ & 10 & 10 \\
\hline
\end{tabular}

*Starch hydrolysate (Nutricia), $2 \mathrm{kcal} / \mathrm{min}$; $\uparrow$ Total amount $5 \mathrm{mmol}$ as sodium salt, Sigma Chemical Company Ltd, $98 \%$ pure: $\ddagger$ For the first $80 \mathrm{~min}$ of GCDC period. Then as control period.

\section{Experiments 7-12 (Fig. 2b)}

Each study comprised an equilibration period (one hour), a control period (two hours), and a GCDC period (two and a half hours). After the tube had reached its position (median 5 hours, range 3 to 6 hours), the jejunum was perfused through $\mathbf{J}$ at $2 \mathrm{ml} /$ min with a solution containing starch hydrolysate $(2$ $\mathrm{kcal} / \mathrm{min}$ ) throughout the experiment to maintain the fed pattern of motility.

The ileum was perfused through port I at $4 \mathrm{ml} / \mathrm{min}$ with saline, except for the first 80 minutes of the GCDC period, when perfusion was done with a solution containing GCDC, total dose $5 \mathrm{mmol}$ (concentration $15 \mathrm{mmol} / \mathrm{l}) .\left[{ }^{14} \mathrm{C}\right] \mathrm{PEG}$ in saline was perfused through $P$ at $1 \mathrm{ml} / \mathrm{min}$ throughout the experiment. One hour into control and GCDC period a bolus of BSP $(50 \mathrm{mg})$ was injected through port I for the measurement of ileal transit. The composition of the test solutions is shown in Table 1 .

Aspiration of ileal fluid was done throughout the study through port A with the help of an air bleed: during the second hour of control and GCDC periods, samples $(2 \mathrm{ml})$ were collected every two minutes for analysis of $\left[{ }^{14} \mathrm{C}\right) \mathrm{PEG}, \mathrm{BSP}$, and bile acids.

In all experiments (1-12), to provide adequate flow for aspiration, lactulose (Table 1) was added to the solutions perfusing the study segment. For the same reason, ileal infusion rate in experiments $7-12$ was

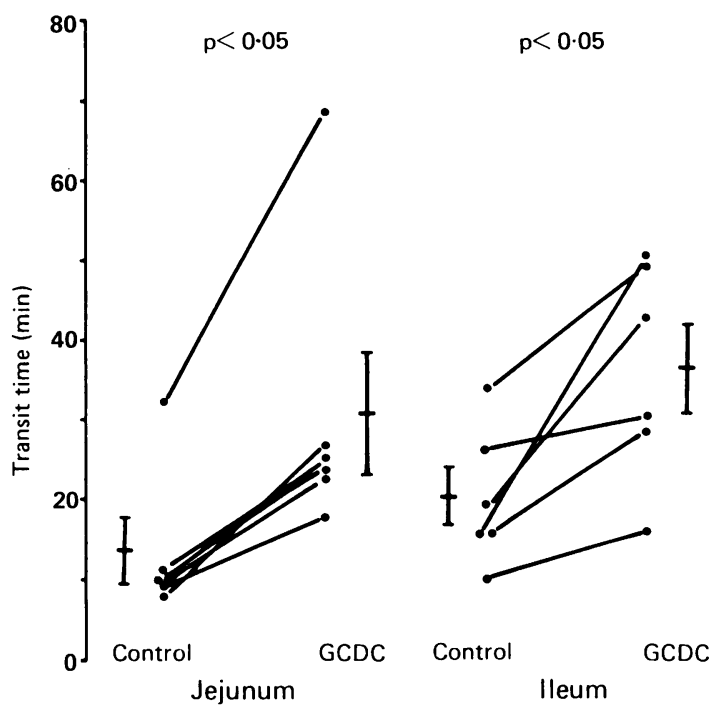

Fig. 3 Effect of ileal infusion of GCDC on jejunal (experiments 1-6) and ileal (experiments 7-12) transit times. Individual values and means (SE).

$4 \mathrm{ml} / \mathrm{min}$ compared with $2 \mathrm{ml} / \mathrm{min}$ in experiments $1-6$, resulting in a lower GCDC concentration. Perfusates were isosmotic and infused by infusion pumps (MHRE MK4 Flow Inducer, Watson-Marlow Ltd, England). Jejunal perfusates were adjusted to $\mathrm{pH} 7$, ileal perfusates to $\mathrm{pH} 7 \cdot 5$.

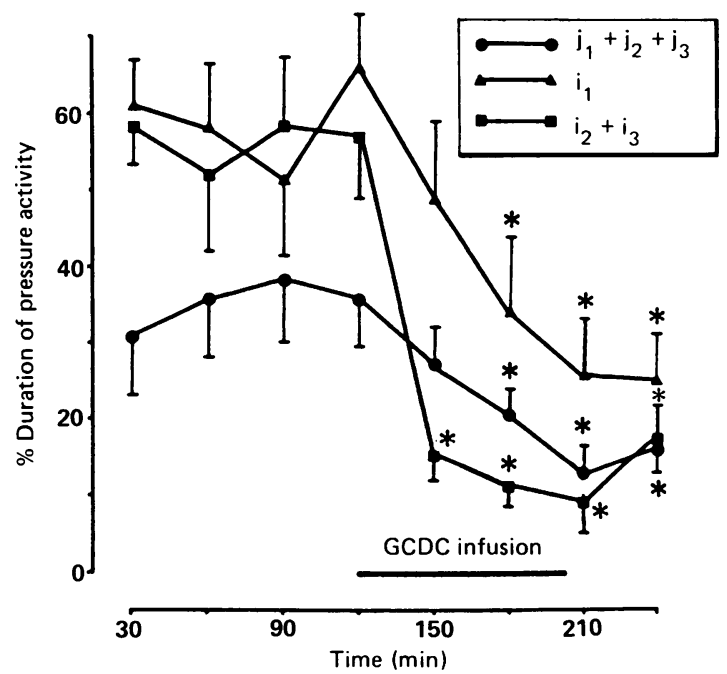

Fig. 4 Experiments 1-6. Effect of ileal infusion of GCDC on percentage duration of pressure activity in the jejunum (O) and in the ileum proximal ( $\mathbf{\Delta})$ and distal ( $\mathbf{\square})$ to the site of GCDC infusion (port I). Symbols show means (SE).

*different from the last 30 min epoch before GCDC infusion begun $(p<0 \cdot 05)$. 
Table 2 Flow rates and segmental volumes (mean $(S E)$ ) during all experiments

\begin{tabular}{lcc}
\hline & Control & \multicolumn{1}{c}{$G C D C$} \\
\hline Jejunum (experiments 1-6) & & \\
$\quad$ Flow rate (ml/min) & $4 \cdot 5(0 \cdot 6)$ & $4 \cdot 6(0 \cdot 6)$ \\
Segment volume $(\mathrm{ml})$ & $59 \cdot 2(9 \cdot 9)$ & $141 \cdot 1(30 \cdot 2)^{*}$ \\
Ileum (experiments 7-12) & & \\
$\quad$ Flow rate $(\mathrm{ml} / \mathrm{min})$ & $4 \cdot 2(0 \cdot 3)$ & $4 \cdot 8(0 \cdot 5)$ \\
Segment volume $(\mathrm{ml})$ & $83.9(9 \cdot 5)$ & $173 \cdot 2(26 \cdot 3)^{*}$ \\
\hline
\end{tabular}

*Different from control $(\mathrm{p}<0 \cdot 05)$.

ANALYSIS OF MANOMETRIC RECORDS

Records were analysed by one author with respect to percentage duration of pressure activity of the fed pattern, dividing the studies into 30 minute epochs. Fluctuations of pressure synchronous with respiration were discarded from analysis. Percentage durations of pressure activity during the 30 minute epochs of the GCDC period were compared with the last 30 minutes of the control period. In experiments $1-6$, data from the jejunal ports $(j 1, j 2, j 3)$ were pooled for analysis. Pressure records from the ileal port situated proximal to the I infusion site (i1) was analysed separately from the pressures recorded by the ileal ports lying distal to the I infusion site $(\mathrm{i} 2, \mathrm{i} 3)$; the data recorded by the two latter ports were pooled for analysis. In experiments 7-12 data from all ileal ports (i1-i5) were pooled for analysis.

Prolonged propagated contractions were defined as rapidly propagated $(>20 \mathrm{~cm} / \mathrm{min}$ ) pressure waves of long duration $(>12 \mathrm{sec})$ and high amplitude $(>50$ $\mathrm{mmHg}) .^{7}$ Onset of inhibition of ileal motility after start of GCDC infusion was arbitrarily computed as the onset of a period of motor quiescence lasting $>5$ min, which had occurred after start of GCDC infusion. Motor quiescence was defined as absence of phasic activity with the exception of isolated prolonged contractions. The criteria of $>5 \mathrm{~min}$ of duration of motor quiescence was chosen because in control periods phasic activity in the ileal tracings was sometimes absent for short periods of time, but never for $>5 \mathrm{~min}$.

ANALYSIS OF $\left[{ }^{14} \mathrm{C}\right] \mathrm{PEG}$ AND BSP

$\left[{ }^{14} \mathrm{C}\right] \mathrm{PEG}$ was measured with a scintillation counter (Beckman LS 7500) using an automatic Quench correction. BSP concentration was estimated with a spectrophotometer (Pye Unicam SP6-500 UV) using a standard method. ${ }^{8}$

ANALYSIS OF BILE ACIDS

Bile acid concentration in the intestinal aspirates was measured with a commercial kit (Sterognost $3 \alpha$ Pho, Nycomed UK) using an automatic spectrophoto- meter (Cobas Mira, Roche) with a good reproducibility $(\mathrm{CV}=4 \cdot 2 \% ; n=10)$.

CALCULATIONS AND STATISTICS

Flow rate was calculated from the dilution of $\left[{ }^{14} \mathrm{C}\right] \mathrm{PEG}$ using standard equations ${ }^{9}$ for the second hour of control and GCDC periods in all experiments. Mean transit time (MTT) and segment volume were determined from the BSP dilution curves as described by Zierler. ${ }^{10}$ Statistical analysis of results, expressed as mean (SE), was done with the paired Wilcoxon's test.

\section{Results}

TRANSIT TIMES, FLOW RATES, AND SEGMENT VOLUMES

Transit times in the jejunum (experiments 1-6) and ileum (experiments 7-12) were markedly $(\mathrm{p}<0.05)$ delayed during infusion of GCDC (Fig. $3 ; 31.6(7 \cdot 7)$ $v 14.5(3.8)$ minutes and $37.0(5.7) v 21.0(3.5)$ minutes, respectively). The delay in transit was associated with increased volume of jejunal and ileal segments (Table 2). Intestinal flow (Table 2) was stable during experiments $1-6$, while it increased slightly but not significantly in five of six subjects during GCDC infusion in experiments 7-12.

MOTILITY

No migrating motor complexes were recorded in any of the studies.

\section{Experiments $1-6$}

Percentage duration of pressure activity decreased markedly in the tracings recorded through i2 and i3 (distal to the I infusion port), after the start of the GCDC infusion (Figs 4-5). Inhibition began 1.5 (0.2) minutes (i2 port) and $2.4(0.5)$ minutes ( $\mathrm{i} 3$ port) after the start of the GCDC infusion and lasted for the whole two hours of the test period. During the first 30 minutes of GCDC infusion isolated high amplitude (50-115 $\mathrm{mmHg})$ waves of long duration (15-30 sec) were present in two subjects: one subject had three, one of which seemed to propagate rapidly from i2 to i3 $(20 \mathrm{~cm} / \mathrm{min})$, the other subject had one in i2 and one in i3, respectively. Proximal to the GCDC infusion port, inhibition in the ileum (i1) and in the jejunum (j1, j2, j3) was less marked and started gradually, reaching significance only during the second 30 minutes of GCDC infusion.

Experiments 7-12

Percentage duration of pressure activity decreased (Figs 6 and 7) in all the $40 \mathrm{~cm}$ of ileum during infusion of GCDC. The inhibition was immediate at the proximal port $\mathrm{i} 1$, starting $1 \cdot 0(0 \cdot 1)$ minute after the 
Fig. 5 Experiments 1-6. Intraluminal pressure records from the jejunum (j1, j2, j3) and ileum proximal (i1) and distal (i2, i3) to the site of GCDC infusion (port I) in one subject at the time GCDC infusion was started. Inhibition of motility distal to the I infusion port occurs shortly after the start of $G C D C$.

start of infusion, while it was progressively more delayed at the more distal ports: $4.1(1.0)$ minutes, $8.7(2.4)$ minutes, $14.5(5.2)$ minutes, and $16.0(5.0)$ minutes at i2, i3, i4 and i5 respectively. Inhibition of motility remained stable in the whole segment for 90

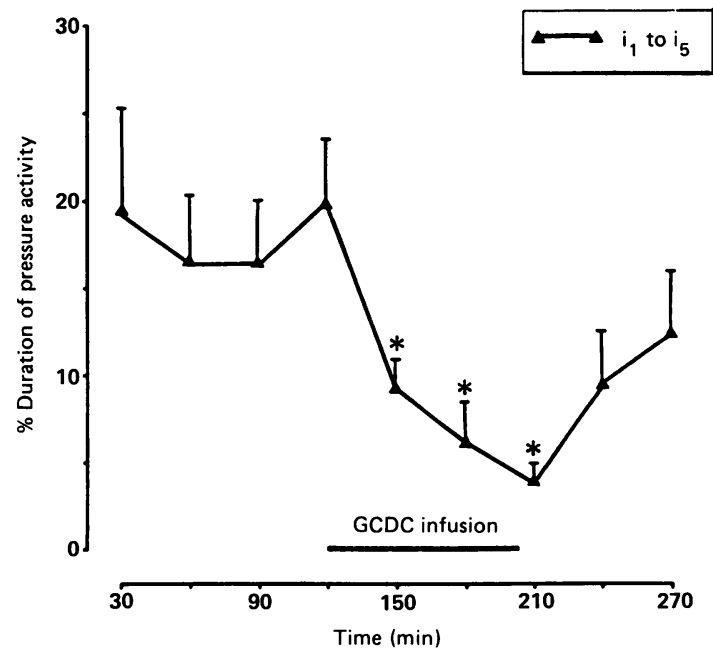

Fig. 6 Experiments 7-12. Effect of ileal infusion of GCDC on percentage duration of pressure activity in the ileum distal $(\Delta)$ to the site of GCDC infusion (port I). Symbols show means (SE). *different from the last 30 min epoch before start of $G C D C$ infusion $(p<0.05)$. minutes and then began to return toward the control values (Fig. 6).

During GCDC infusion isolated prolonged (12-18 sec), high amplitude (50-105 $\mathrm{mmHg}$ ) waves were recorded (Fig. 8) in three subjects: in one subject the three waves were present in one port (i1, i2, i4) at a time; in a second subject two prolonged contractions propagated $(70-90 \mathrm{~cm} / \mathrm{min})$ along the four proximal ports. The third subject had four prolonged contractions (all in the first 30 minute period of GCDC infusion) propagated $(35-90 \mathrm{~cm} / \mathrm{min})$ along two to four ports. There were no subjective symptoms coinciding with the high amplitude waves.

INTESTINAL BILE ACID CONCENTRATIONS

Intestinal bile acid concentrations (Table 3 ) were similar during control and GCDC periods in experiments $1-6$. In experiments $7-12$ bile acid concentrations increased significantly $(p<0.05)$ during GCDC infusion and showed absorption of some of the infused bile acid. Considering that GCDC was infused at $60 \mu \mathrm{mol} / \mathrm{min}$ and that at the aspiration site during the GCDC period bile acid flow was $32 \cdot 5(7 \cdot 1)$ $\mu \mathrm{mol} / \mathrm{min}$, subtracting the control bile acid flow at the aspiration site $(4.9(2.2) \mu \mathrm{mol} / \mathrm{min})$, an absorption of $54 \cdot 0(9 \cdot 3) \%$ GCDC by the $40 \mathrm{~cm}$ ileal segment can be estimated. These calculations assume that input of endogenous bile acids was constant during the whole study, assumption which seems justified by 


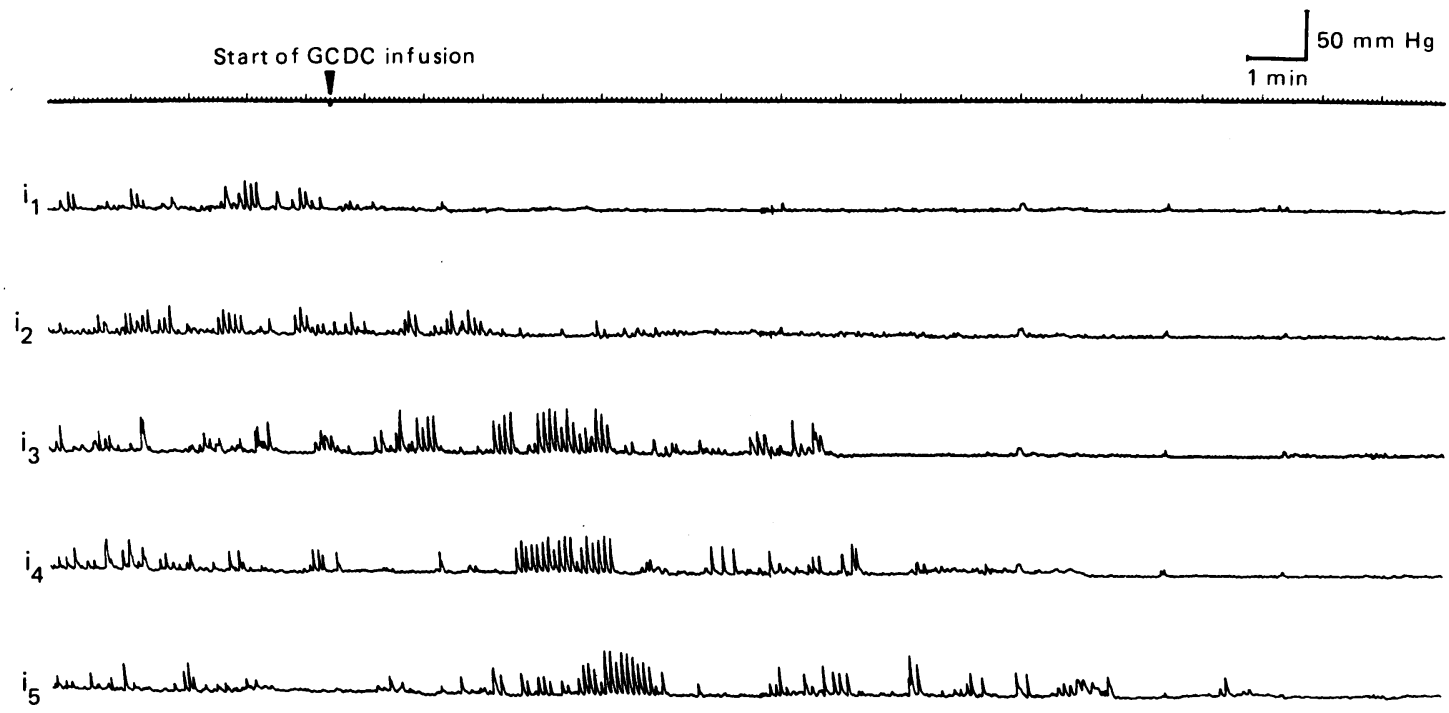

Fig. 7 Experiments 7-12. Intraluminal pressures from the ileum distal (i1-i5) to the site of GCDC infusion (port I) in one subject at the start of GCDC infusion. Inhibition of motility is recorded in the whole $40 \mathrm{~cm}$ ileal segment.

steady intestinal bile acid concentrations during experiments $1-6$.

\section{SIDE EFFECTS}

In experiments $1-6$ one subject experienced central abdominal discomfort lasting for one hour during GCDC infusion. His motility record was similar to the other symptom free subjects.

\section{Discussion}

This study showed that when GCDC, one of the two predominant primary bile acids in man, ${ }^{11}$ was infused into the ileum an inhibition of motility at sites in the

Table 3 Intestinal concentrations of bile acids ( $\mathrm{mmol} / \mathrm{l}$; mean (SE)) during all experiments

\begin{tabular}{ccc}
\hline & Control & GCDC \\
\hline Jejunum (experiments 1-6) (min) & & \\
$60-75$ & $1 \cdot 2(0 \cdot 5)$ & $0 \cdot 6(0 \cdot 2)$ \\
$75-90$ & $1 \cdot 2(0 \cdot 5)$ & $1 \cdot 7(1 \cdot 2)$ \\
$90-105$ & $1 \cdot 6(0 \cdot 7)$ & $1 \cdot 5(0 \cdot 9)$ \\
$105-120$ & $0 \cdot 9(0 \cdot 3)$ & $0 \cdot 6(0 \cdot 2)$ \\
Average (60-120) & $1 \cdot 2(0 \cdot 5)$ & $1 \cdot 1(0 \cdot 6)$ \\
Ileum (experiments 7-12)(min) & & \\
$60-75$ & $1 \cdot 2(0 \cdot 5)$ & $5 \cdot 3(1 \cdot 1)^{*}$ \\
$75-90$ & $0 \cdot 9(0 \cdot 3)$ & $5 \cdot 6(0 \cdot 6)^{*}$ \\
$90-105$ & $0 \cdot 6(0 \cdot 2)$ & $5 \cdot 4(1 \cdot 2)^{*}$ \\
$105-120$ & $0 \cdot 7(0 \cdot 5)$ & $4 \cdot 8(1 \cdot 0)^{*}$ \\
Average $(60-120)$ & $0 \cdot 8(0 \cdot 3)$ & $5 \cdot 2(1 \cdot 0)^{*}$ \\
\hline
\end{tabular}

*Different from control $(\mathrm{p}<0.05)$. jejunum and the ileum was triggered. As a result of the inhibition, no increase was observed in ileal flow during GCDC infusion despite its secretory action. ${ }^{5}$

Intraluminal pressure responses distal and proximal to the GCDC infusion site appear to be different. Distal to the infusion port (experiments $1-6$ and 7-12) inhibition of pressure activity was almost immediate at the more proximal ports and progressively delayed at the ports more distal from the infusion site. These data suggest that the inhibitory effect was mediated by direct contact between GCDC and mucosal chemoreceptors sensitive to the bile acid. Furthermore this pattern of response seems to be site-specific for the ileum, because perfusing the jejunum with the same infusate triggers a delayed, more gradual inhibition of jejunal motility. ${ }^{1}$

Proximal to the infusion port (experiments 1-6), inhibitory response was slower to start and more gradual. In addition, proximal inhibition of pressure activity did not appear to need intraluminal presence of the bile acid, as the jejunal concentration of bile acids remained in the fasting range during the GCDC period (Table 3), ${ }^{12}$ suggesting that the infused GCDC, at least partly absorbed by the ileum during the experiment, did not circulate significantly from the liver back into the small intestine. As distention of an intestinal segment is known to produce inhibition of motility in the remainder of the intestine,$^{1314}$ it is possible that distention of the ileum distal to the GCDC infusion port (Table 2) caused by the motor and secretory effects of the bile acid was the determinant of inhibition of motility in the proximal intestine. 


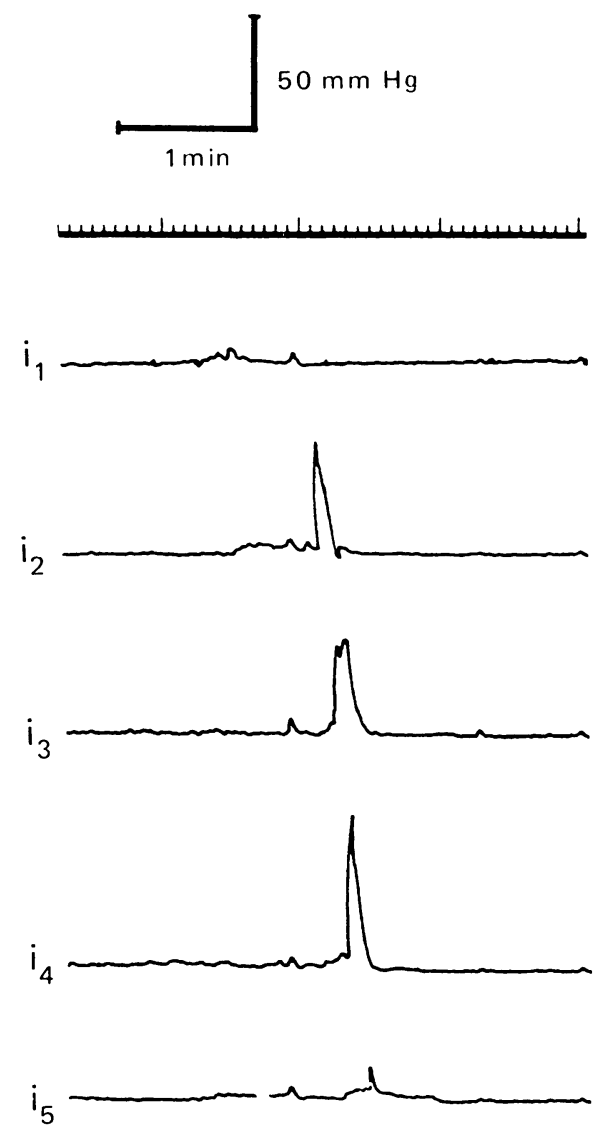

Fig. 8 Experiments 7-12. Intraluminal pressures from the ileum distal ( $i l-i 5)$ to the site of GCDC infusion (port I) in one subject during GCDC infusion. Prominent is a single contraction lasting $12 \mathrm{sec}$, rapidly propagated aborally (prolonged propagated contraction).

The ileal inhibitory reflex provoked by fat, which has been characterised recently, ${ }^{23}$ is likely to be operating in patients with steatorrhoea, but its presence in healthy people is still uncertain. By contrast, the inhibitory reflex described in this paper may be present after meals in healthy people, as infusion rates and concentrations of GCDC mimicked the postprandial secretion rates and intestinal concentrations of endogenous bile acids in healthy subjects. ${ }^{12}{ }^{15}$ Although an additional bile acid pool in the form of GCDC was given to our volunteers, our experimental model allowed us to study the fed state without stimulation of endogenous bile acid secretion, thus excluding the endogenous pool and an unphysiological overload of bile acids to the small intestine. During jejunal infusion of starch hydrolysate small bowel motility was in the fed state and intestinal concentrations of bile acids (when cor- rected for the infusion rate) were in the fasting range: ${ }^{2}$ throughout the studies, except in the ileum at the time of GCDC infusion. Bile acids are necessary for absorption of fat ${ }^{16}$ and they are actively absorbed in the distal small bowel. ${ }^{17}$ Therefore, although caution should be observed in extrapolating experimental findings to the real life situation, it can be postulated that the mechanism recorded here is likely to optimise absorption and minimise escape of bile acids into the large bowel.

A further interesting observation was that, although inhibiting motility, infusion of GCDC evoked prolonged, high amplitude, isolated contractions in the ileum of some of the subjects. In two subjects (experiments 7-12) the contractions were rapidly propagated distally along varying lengths of bowel. To our knowledge there are no reports of such waves in the ileum of healthy humans during the fed state and their occurrence after GCDC needs further study. Prolonged contractions propagated along the terminal ileum and sometimes crossing the ileocaecal sphincter have been reported in $\operatorname{man}^{7}$ and the $\operatorname{dog}^{19}$ during the fasted pattern of motility. In the dog they have been shown to last longer than a single slow wave, to propel fluid and to be evoked by local stimuli such as distention, volatile fatty acids and chenodeoxycholic acid. ${ }^{2122}$ The present experiments do not indicate whether the prolonged propagated contractions observed were triggered by distention of the ileal segment occurring during GCDC infusion, or by GCDC itself. Furthermore, it is unlikely that the occurrence of these waves in the presence of GCDC makes a major contribution to ileal transit as they were recorded in less than half of the experiments and were propagated only on a few occasions.

\section{References}

1 Penagini R, Misicwicz JJ. Frost PG. Effect of jejunal infusion of bile acids on small bowel transit and fasting jejunal motility in man Gut 1988: 29: 789-94.

2 Spiller RC, Trotman IF, Higgins BE, et al. The ileal brake - inhibition of jejunal motility after ileal fat perfusion in man. Gut 1984; 25 : 365-74.

3 Read NW, McFarlane A. Kinsman RI, et al. Effect of infusion of nutrient solutions into the ileum on gastrointestinal transit and plasma levels of neurotensin and enteroglucagon. Gastroenterology 1984; 86: 274-80.

4 Spiller RC. Brown ML, Phillips SF. Decreased fluid tolerance, accelerated transit, and abnormal motility of the human colon induced by oleic acid. Gastroenterology 1986; 91 : 100-7.

5 Krag E, Phillips SF. Effect of free and conjugated bile acids on net water, electrolyte, and glucose movement in the perfused human ileum. J Lab Clin Med 1974; 83: 947-56. 
6 Phillips SF, Summerskill WH. Occlusion of the jejunum for intestinal perfusion in man. Mayo Clin Proc 1966; 41: 224-31.

7 Quigley EMM, Borody TJ, Phillips SF, Wienbeck M, Tucker RL, Haddad A. Motility of the terminal ileum and ileocecal sphincter in healthy humans. Gastroenterology 1984; 87: 857-66.

8 Dillard RL, Eastman H, Fordtran JS. Volume-flow relationship during the transport of fluid through the human small intestine. Gastroenterology 1965; 49: 5866.

9 Phillips SF, Giller J. The contribution of the colon to electrolyte and water conservation in man. J Lab Clin Med 1973; 81: 733-46.

10 Zierler KL. A simplified explanation of the theory of indicator-dilution for measurement of fluid flow and volume and other distributive phenomena. Bull John Hopkins Hosp 1958; 103: 199-217.

11 Hofmann AF. The enterohepatic circulation of bile acids in man. In: Paumgartner G, ed. Clinics in gastroenterology vol VI. Bile acids. London: WB Saunders Company, 1977: 3-24.

12 Northficld TC, McColl I. Postprandial concentrations of free and conjugated bile acids down the length of the normal human small intestine. Gut 1973; 14: 513-8.

13 Chang PY, Hsu FY. The localization of the intestinal inhibitory reflex arc. $Q J$ Exp Physiol 1942; 31: 311-8.
14 Johansson B, Jonsson O, Ljung B. Supraspinal control of the intestino-intestinal inhibitory reflex. Acta Physiol Scand 1965; 63: 442-9.

15 Brunner H, Northfield TC, Hofmann AF, Go VLW, Summerskill WHJ. Gastric emptying and secretion of bile acids, cholesterol, and pancreatic enzymes during digestion. Mayo Clin Proc 1974; 49: 851-9.

16 Hofmann AF, Rainer Poley J. Role of bile acid malabsorption in pathogenesis of diarrhea and steatorrhea in patients with ileal resection. Gastroenterology 1972; 62: 918-34.

17 Weiner IM, Lack L. Absorption of bile salts from the small intestine in vivo. Am J Physiol 1962; 202: 155-7.

$18 \mathrm{Krag}$ E, Phillips SF. Active and passive bile acid absorption in man. J Clin Invest 1974; 53: 1686-94.

19 Quigley EMM, Phillips SF, Dent J. Distinctive patterns of interdigestive motility at the canine ileocolonic junction. Gastroenterology 1984; 87: 836-44.

20 Kruis W, Azpiroz F, Phillips SF. High pressure propulsive forces of the canine ileum [Abstract]. Clin Res 1983; 31: $746 \mathrm{~A}$.

21 Kruis W, Azpiroz F. Phillips SF. Contractile patterns and transit of fluid in canine terminal ileum. Am J Physiol 1985; 249: 264-70.

22 Kamath PS, Hoepfner MT, Phillips SF. Volatile fatty acids stimulate ileal peristalsis. Gastroenterology 1986; 90: 1482 . 